\title{
O exame médico pré-nupcial em debate: uma proposta de intervenção eugênica no Brasil, 1910-1940
}

\author{
Prenuptial medical exams in debate: a proposed eugenic \\ intervention in Brazil, 1910-1940
}

\section{Priscila Bermudes Peixoto}

Mestranda em História e Cultura Social/Universidade Estadual Paulista Júlio de Mesquita Filho. Av. Eufrásia Monteiro Petráglia, 900 14409-160 - Franca - SP - Brasil priscilabermudes1@gmail.com
PEIXOTO, Priscila Bermudes. O exame médico pré-nupcial em debate: uma proposta de intervenção eugênica no Brasil, 1910-1940. História, Ciências, Saúde - Manguinhos, Rio de Janeiro, v.23, supl., dez. 2016, p.253259.

Resumo

Este texto resulta da pesquisa que desenvolvo para minha dissertação de mestrado, cuja temática central é a proposta do exame médico pré-nupcial nas primeiras décadas do século XX no Brasil. Tal medida foi amplamente defendida por eugenistas brasileiros por ser considerada necessária e imprescindível ao aprimoramento racial da população. Por meio desse exame pretendia-se impedir a união e reprodução de indivíduos considerados degenerados ou inferiores, vistos como inadequados para a formação eugênica das futuras gerações. Procura-se analisar o debate desenvolvido no Brasil por médicos e intelectuais favoráveis à implantação de uma lei que instituísse a obrigatoriedade do exame pré-nupcial, assim como as controvérsias e objeções reclamadas por seus críticos, contribuindo para que essa imposição não fosse adotada no país.

Palavras-chave: eugenia; exame pré-nupcial; medicina; casamentos; reprodução.

\section{Abstract}

This text results from research undertaken for a master's degree that focused on the proposed introduction of prenuptial medical exams in the early 1900s in Brazil. This was strongly defended by Brazilian eugenicists as a much-needed means of bringing about the racial improvement of the population. The exam would help prevent the marriage and reproduction of individuals considered degenerate or inferior, seen as inadequate for the eugenic development of future generations. The debate in Brazil between doctors and intellectuals who supported the introduction of a law that would make a prenuptial medical exam mandatory is analyzed, as are the controversies and objections voiced by its critics, ultimately helping ensure it was not adopted in the country.

Keywords: eugenics; prenuptial exam; medicine; marriage; reproduction. 
A discussão acerca do exame médico pré-nupcial, de acordo com o médico e eugenista Renato Kehl, ${ }^{1}$ antecede ao próprio debate sobre eugenia no Brasil. Segundo o autor, o médico Agostinho de Souza Lima foi um dos primeiros intelectuais brasileiros a defender a exigência desse exame como requisito para autorizar a realização de matrimônios, tendo solicitado, ainda em 1897, o apoio da Academia Nacional de Medicina para tornar tal exame obrigatório por lei, buscando o impedimento matrimonial aos sifilíticos ou tuberculosos. Souza Lima, nos dizeres de Renato Kehl, foi considerado um dos precursores nos esforços em "sanear" os matrimônios (Kehl, 1929, p.52).

No Brasil, o discurso eugênico ganharia força a partir da década de 1910, com as primeiras produções de artigos e teses médicas, bem como a formação de associações especializadas, como a Sociedade Eugênica de São Paulo, criada em 1918 (Stepan, 2005; Souza, 2006). Em sua busca do aprimoramento racial, os adeptos da eugenia voltariam suas atenções para a questão da educação sexual e do controle matrimonial. Apesar de existir um considerável número de uniões não conjugais no país, de modo geral, ao menos do ponto vista moral e religioso, a formação familiar se dava a partir da união oficializada entre um homem e uma mulher, ou seja, a partir do matrimônio formalizado. Essa instituição passa a ser objeto de preocupação e atenção dos eugenistas, uma vez que desses casamentos surgiriam as proles responsáveis pelo futuro da nação brasileira. Casamentos entre indivíduos considerados fracos, doentes, loucos ou degenerados implicavam supostamente a constituição de proles inúteis e prejudiciais ao avanço nacional. O exame médico pré-nupcial surgia, na concepção de médicos e eugenistas, como uma ação preventiva e necessária para o melhoramento racial da população.

Entre os que defendiam essa medida, havia a compreensão de que os nubentes - homens e mulheres - deveriam passar por um exame por meio do qual um especialista médico iria determinar se aqueles indivíduos possuíam condições de contrair matrimônio e constituir prole forte e saudável. Nota-se, assim, a inegável preocupação eugênica com a hereditariedade. Nesse período, apesar de boa parte dos médicos reconhecer que a ciência ainda não possuía total conhecimento da forma como atuavam os mecanismos da hereditariedade, entendiam que ninguém estava em condições de negar que as transmissões hereditárias existiam, conforme explicava o jurista Teodolindo Castiglione (1942, p.7). Desse modo, do ponto de vista eugênico, era necessário que medidas fossem tomadas para que se evitasse a propagação de fatores disgênicos para outras gerações; em outras palavras, buscavam impedir a transmissão da "má descendência". Segundo os eugenistas, os estudos apontavam que quando pessoas sãs se uniam havia mais chances de ter uma prole sadia. Por sua vez, um casal de "tarados" ou fisicamente defeituosos só poderia esperar uma descendência nas mesmas condições: "Daí a Eugenia ensinar que convém promover aquelas uniões e evitar estas últimas" - enfatizava o eugenista Octávio Domingues (1942, p.31).

O exame pré-nupcial era defendido, sobretudo, por médicos eugenistas, mas também por educadores, jornalistas e autoridades públicas. É importante ressaltar que, nesse período, os médicos se consideravam os profissionais mais aptos para normatizar comportamentos, hábitos de higiene, modos de comer e vestir etc. Segundo Nancy Stepan (2005, p.50), no início do século XX, a medicina passava a expandir seu papel social e sua pretensão de intervir na organização e reforma da sociedade. Não bastava apenas curar os enfermos ou indicar 
cuidados de saúde, os médicos agora se preocupavam com questões mais amplas, de caráter coletivo, como a salubridade das cidades, das moradias, a qualidade do ar e da água, ou seja, formas de prevenir a propagação de epidemias e doenças que supostamente atravancavam o progresso nacional.

A argumentação em torno do exame pautava-se no fato de que o homem moderno não poderia mais confiar em seus instintos na escolha de seu companheiro-cônjuge (Almeida Jr., 1927, p.10), além disso, os eugenistas acreditavam que poderiam tomar providências para antecipar ou acelerar o processo de seleção natural. Luciano de Mello Batista (1926, p.10), em sua tese apresentada à Faculdade de Medicina do Rio de Janeiro, questionava o motivo de deixar que a espécie humana caísse na ruína, se os homens dotados de inteligência poderiam, "escudados pela Eugenia, remover tropeços e empecilhos que retardam a nossa marcha para um futuro mais perfeito, para a regeneração física e moral da nossa raça". Dentro dessa concepção, parecia evidente que os médicos eugenistas deveriam intervir nas uniões matrimoniais, impedindo que aqueles indivíduos considerados degenerados se reproduzissem. Desse modo, ficava estabelecido, conforme afirmava o psiquiatra Júlio Pires de Porto-Carrero (1933, p.88), que, sob o ponto de vista eugênico, seria ideal que apenas pudessem casar-se indivíduos completamente hígidos e em condições de procriar filhos física e psiquicamente perfeitos.

Supostamente, portanto, era preciso que os casamentos fossem "eugenizados", e, por meio do exame pré-nupcial, acreditava-se que seria possível estabelecer uma seleção conjugal e garantir a profilaxia da raça (Batista, 1926, p.43). Dadas a proclamada importância e a necessidade dessa medida, os eugenistas defendiam a existência de uma lei aplicável em todo o país que tornasse o exame obrigatório. Além da tentativa de Souza Lima, já citada, temos conhecimento de outros projetos de lei: em 1927 era apresentado ao Congresso Nacional o projeto do médico e deputado Amaury de Medeiros, no qual se propunha: "Além dos documentos mencionados no art. 180 do Código Civil para a habilitação do casamento, deverá figurar um certificado médico datado de cinco dias" (Castiglione, 1942, p.126). Entretanto, seria facultativo o pedido do exame, podendo ser legalmente requerido quando um dos nubentes ou seus pais considerassem necessário. Mais tarde, outro projeto de lei para adoção do exame foi bastante discutido pela Assembleia Constituinte de 1933-1934 (Stepan, 2005, p.134-135). Contudo, em que pese os insistentes esforços, o exame pré-nupcial não foi convertido em lei, ao menos da forma como os médicos eugenistas ambicionaram, uma vez que nunca foi implantada sua obrigatoriedade em âmbito nacional. ${ }^{2}$

A proposta do exame pré-nupcial não era singularidade brasileira. Em vários países foi amplamente debatida, e em alguns deles, como México, Argentina, Suécia, Turquia e alguns estados norte-americanos, chegou-se a implantar a exigência do exame (Stepan, 2005, p.131136). Nesse sentido, uma das perguntas que movem nossa pesquisa é: uma vez que existiam tantos defensores, por qual(is) motivo(s) a obrigatoriedade do exame pré-nupcial não foi implantada no Brasil? Para responder essa questão é necessário que se faça uma investigação aprofundada acerca dos aspectos médicos, culturais e sociais do país e o modo como poderiam ter influenciado para que o exame não se tornasse uma exigência legal para a realização de matrimônios. 
Até o momento pudemos mapear algumas hipóteses, lembrando, entretanto, que essa pesquisa ainda está sendo desenvolvida. Nota-se que os médicos eugenistas reconheciam algumas objeções em relação ao exame. Havia amplo debate em torno dessa medida; aqueles que a questionavam ou eram contrários a ela costumavam argumentar que o exame prénupcial seria um atentado à liberdade individual, uma vez que os médicos teriam poder de determinar quem poderia ou não se casar. Sob a perspectiva eugenista não bastava que o exame fosse realizado e os médicos apenas aconselhassem os nubentes, deixando a decisão nas mãos destes últimos. Logo, os médicos eugenistas brasileiros ambicionavam que os exames fossem realizados e que a decisão final da possibilidade do matrimônio ficasse a seu critério. Sobre a questão de o exame atentar à liberdade individual, o psiquiatra Porto-Carrero (1933, p.89) argumentava nos Arquivos Brasileiros de Higiene Mental:

$\mathrm{O}$ argumento da liberdade individual, contrapondo-se a essas exigências, rui pela base, desde que lembremos que a liberdade de cada um cessa onde começa o direito de outrem e, mais acentuadamente ainda, onde começa o interesse legítimo da coletividade. Em sociedade, todos os direitos individuais são restritos, ante o direito coletivo; e a ninguém cabe o direito de contaminar. Antes, o delito de contaminação está previsto em vários Códigos modernos e em vias de entrar em nosso.

De modo semelhante, segundo o médico Antônio Almeida Jr. (1927, p.33), a liberdade não daria o direito de infectar o outro; além disso, o casamento seria uma instituição de ordem pública e interessaria mais à sociedade que aos cônjuges. Questionava-se também se tal exame seria um atentado ao segredo profissional e quem deveria realizá-lo: o médico da família ou um médico perito, especializado para exercer tal função? Do ponto de vista de Luciano de Mello Batista (1926, p.85), seria ideal que um perito realizasse o exame pré-nupcial, uma vez que, dessa forma, o segredo profissional deixaria de ser uma questão: “o atestado não deverá nunca ser fornecido pelo médico da família, mas por um perito, nomeado exclusivamente para este fim, que, segundo o professor Souza Lima, desempenha o seu cargo fora das leis do segredo profissional". De modo geral, os eugenistas argumentavam favoravelmente à existência de médicos especialistas para realizar o referido exame, pois acreditava-se que, caso os médicos de família pudessem dar tal diagnóstico, maiores seriam as chances de ocorrer falsificações, ou seja, manipulação dos atestados em razão de possíveis relações amigáveis entre médico e paciente-nubente.

Além dessas objeções éticas, existiam também motivos práticos que supostamente impediriam a implantação do exame médico pré-nupcial por lei. Esses, muito provavelmente, eram os que mais preocupavam os eugenistas, já que se reconhecia sua validade, e as soluções não eram tão simples. Uma dessas objeções práticas seria em relação à aplicação da lei em todo o território nacional. Os médicos eugenistas, como Júlio Pires de Porto-Carrero (1933), por exemplo, acreditavam que a medicina brasileira tinha condições e estava regularmente aparelhada para realizar tais diagnósticos, mas apenas nos grandes centros urbanos. Logo, questionavam como poderiam ser realizados tais exames na zona rural, "nos rincões incultos do país" (p.91).

A partir da análise das fontes, como teses médicas, livros, periódicos científicos e jornais, podemos notar que boa parte dos intelectuais reconhecia a importância e a utilidade do exame pré-nupcial. Teodolindo Castiglione (1942, p.133), ao avaliar as discussões travadas na 
Assembleia Constituinte de 1934, afirma que "Não se negava a utilidade do exame pré-nupcial: o que dividia as opiniões era a oportunidade ou modo de introduzi-lo. Se os constituintes tivessem a convicção de que a medida que se pretendia implantar dava bons resultados práticos, ninguém a impugnaria". Portanto, o que causava ainda muitas divergências era sua forma de aplicação como lei, se essa seria possível e se conseguiria, afinal, cumprir sua suposta função de impedir a reprodução dos degenerados.

Os médicos eugenistas também discutiam se o exame deveria ser incluído na lei como facultativo ou obrigatório. Para Júlio Porto-Carrero e também para a cirurgiã-ginecologista Juana M. de Lopes, a legislação de teor facultativo seria inócua, pois, segundo ambos, nada proibia o indivíduo de exigir de seu noivo(a) tal exame, logo não seria necessário uma lei que o facultasse. No entanto, os dois médicos também acreditavam que não bastava tornar o exame obrigatório se a população em geral não compreendesse sua utilidade e importância (Lopes, 1933, p.107). Para Almeida Jr. (1927, p.66), era preciso investir numa intensa propaganda e educação eugênica, caso contrário, se o exame fosse aprovado por lei sem que antes fossem realizadas essas medidas, causaria uma provável repulsa popular brasileira, por ser uma lei que iria restringir um direito tão ciosamente defendido como o de casar. A população acabaria, nesse sentido, por fraudar, desobedecer, enfim, encontrar maneiras para burlar a legislação. Desse modo, aos olhos dos eugenistas, as questões práticas pareciam ser mais difíceis de solucionar do que as questões "doutrinárias" ou "éticas":

A nosso ver, não são os motivos éticos que impedirão introduzir a referida medida, mas as dificuldades materiais para a sua fácil realização. Com uma boa propaganda, todos acabarão por compreender que uma descendência de doentes, e isto sob o ponto de vista egoístico, individual, não concorre para a formação de uma família feliz. Além de maiores gastos que acarreta, uma prole doentia é uma fonte de amarguras (Castiglione, 1942, p.137).

No estágio em que se encontra nossa pesquisa, ainda não podemos afirmar com precisão por qual(is) motivo(s) a obrigatoriedade nacional do exame pré-nupcial não foi implantada no Brasil. As objeções que aqui pontuamos de fato existiam e estiveram presentes em várias discussões sobre o tema. Além disso, se faz necessária uma investigação sobre o posicionamento da Igreja católica em relação ao exame, uma vez que temos conhecimento de que representantes dessa instituição se posicionaram muitas vezes de forma crítica às propostas eugênicas, sobretudo diante daquelas que se referiam aos métodos contraceptivos (Mai, 2003, p.59; Wegner, Souza, 2013).

No caso brasileiro, até o momento encontramos apenas propostas de impedimentos matrimoniais aos indivíduos que possuíssem enfermidades contagiosas ou hereditárias, que possuíssem deficiências físicas ou mentais, cônjuges com grande diferença de idade ou que tivessem grau de parentesco próximo, configurando assim o que chamavam de "casamentos consanguíneos". O eugenista argentino Victor Delfino (1929, p.2), em artigo ao Boletim de Eugenia, explicita bem o objetivo do exame pré-nupcial: "cuja função principal é evitar as enfermidades que se podem transmitir por contágio de qualquer natureza, entre os homens". Dessa forma, uma das questões colocadas para essa pesquisa é saber em que medida outros aspectos, como a questão dos impedimentos aos casamentos interraciais, estiveram presentes nesse debate. Nos Estados Unidos, conforme aponta Nancy 
Stepan (2005, p.189), teriam existido leis proibindo matrimônios inter-raciais, o que, segundo a autora, fez com a eugenia estadunidense parecesse mais racista que a latina. Há que considerar, contudo, que parte dos presentes no Primeiro Congresso Brasileiro de Eugenia (1929) aconselhava a exclusão de todas as correntes migratórias que não fossem de raça branca; além disso, nesse mesmo congresso, o então presidente da Academia Nacional de Medicina, Miguel Couto, defendia "a tese de que a mistura racial levaria à degeneração nacional" (Schwarcz, 1993, p.308). Nesse sentido, um dos questionamentos colocados em nossa pesquisa concerne ao motivo de não estarem explicitados impedimentos matrimoniais inter-raciais nas propostas do exame pré-nupcial, uma vez que se nota o forte debate existente em torno da miscigenação e uma concepção muitas vezes ainda bastante negativa dela.

As fontes utilizadas para esta investigação são diversas, vão desde aqueles documentos do âmbito acadêmico, como revistas e teses médicas, passando por publicações voltadas apenas para a temática da eugenia, como o periódico Boletim de Eugenia e as Atas do Primeiro Congresso Brasileiro de Eugenia, além dos Arquivos Brasileiros de Higiene Mental, no qual o tema do exame também foi colocado em questão. No entanto, em jornais destinados à população em geral também encontramos reportagens sobre o assunto, como em O Globo, por exemplo, que deu destaque para as discussões sobre o referido exame. Por ter sido projeto de lei conforme pontuamos anteriormente -, também faz-se necessária a análise das discussões que ocorriam nas assembleias legislativas, sobretudo na constituinte de 1933-1934.

Conforme se pretendeu demonstrar, a suposta regulamentação do casamento sob bases eugênicas, por meio do exame pré-nupcial, tinha por principal objetivo vetar o matrimônio aos indivíduos portadores de moléstias consideradas graves e transmissíveis que, nessa concepção, poderiam comprometer a procriação hígida, logo, o aprimoramento racial. A partir da análise das fontes, nota-se que, apesar de certos eugenistas desaconselharem algumas uniões inter-raciais, não se encontra explicitado nas propostas de tal exame nenhum tipo de impedimento ou proibição matrimonial aos casais de raças diferentes. Desse modo, tais observações suscitam a hipótese de que a proposta eugênica do exame pré-nupcial esteve fortemente ligada à questão da saúde, pensada como elemento fundamental para o melhoramento da raça. Em diálogo com outros autores como Nancy Stepan, por exemplo, sugere-se que a saúde e a formação de proles saudáveis eram fatores tão caros aos eugenistas brasileiros quanto o "branqueamento" racial, ou pelo menos para parte deles, uma vez que não constituíam um grupo homogêneo. Outro ponto importante a ser analisado em nossa pesquisa refere-se ao fato de que, em âmbito nacional, o referido exame nunca se constituiu como um requisito obrigatório para a efetuação do casamento civil. Supondo assim os limites da intervenção eugênica, resta saber, entretanto, em que medida esses "limites" foram impostos por motivos doutrinários ou práticos (falta de aparato médico e laboratorial, por exemplo). Embora já exista uma historiografia consolidada sobre a eugenia, entendemos que sua temática não esteja esgotada, haja vista que não há um estudo aprofundado com ênfase no exame médico pré-nupcial. Acreditamos que este estudo, por sua vez, poderá contribuir para melhor compreensão do movimento eugênico no Brasil. 


\section{NOTAS}

${ }^{1}$ Renato Kehl formou-se na Faculdade de Medicina do Rio de Janeiro em 1915 e foi um dos maiores divulgadores da eugenia no Brasil. Em 1918 fundou a Sociedade Eugênica de São Paulo, foi editor do periódico Boletim de Eugenia (1929-1933), além de também ter sido fundador da Comissão Central Brasileira de Eugenia, em 1931 (Souza, 2006, p.68-71).

${ }^{2} \mathrm{O}$ artigo 145 da Constituição de 1934 exigia prova de sanidade física e mental aos futuros cônjuges. No entanto, sua aplicação levaria em consideração as condições regionais do país (Stepan, 2005, p.135). Sendo assim, o exame pré-nupcial não foi implantado da forma como almejaram os eugenistas, ou seja, de modo obrigatório em todo o país.

\section{REFERÊNCIAS}

ALMEIDA JR., Antônio.

O exame médico pré-nupcial. São Paulo: Instituto Dona Anna Rosa. 1927.

BATISTA, Luciano de Mello.

Do exame pré-nupcial como fator eugênico. Tese apresentada à Faculdade de Medicina do Rio de Janeiro, Rio de Janeiro. 1926.

CASTIGLIONE, Teodolindo.

A eugenia no direito de família. São Paulo: Saraiva \& Cia. 1942.

DELFINO, Victor.

$\mathrm{O}$ atestado médico pré-nupcial. Boletim de Eugenia, ano 1, n.12, p.2-3. dez. 1929.

DOMINGUES, Octávio.

Eugenia: seus propósitos, suas bases, seus meios (em cinco lições). São Paulo: Companhia Editora Nacional. 1942.

KEHL, Renato.

A eugenia no Brasil. In: Primeiro Congresso Brasileiro de Eugenia, Rio de Janeiro, 1929, Actas e trabalhos... Rio de Janeiro, s.n., v.1, p.45-63. 1929.

LOPES, Juana M.

Em torno do exame pré-nupcial. Archivos Brasileiros de Higiene Mental, v.6, n.2, p.103-122. 1933.
MAI, Lilian Denise.

Difusão dos ideários higienistas e eugenistas no Brasil. In: Boarini, Maria Lucia (Org.). Higiene e raça como projetos: higienismo e eugenismo no Brasil. Maringá: Eduem. 2003.

PORTO-CARRERO, Júlio Pires de.

O exame pré-nupcial como fator eugênico. Arquivos Brasileiros de Higiene Mental, v.6, n.2, p.87-94. 1933.

SOUZA, Vanderlei Sebastião de.

A política biológica como projeto: a "eugenia negativa" e a construção da nacionalidade na trajetória de Renato Kehl (1917-1932). Dissertação (Mestrado) - Programa de Pósgraduação em História das Ciências da Saúde da Casa de Oswaldo Cruz/Fiocruz, Rio de Janeiro. 2006.

SCHWARCZ, Lilia Moritz.

O espetáculo das raças: cientistas, instituições e questão racial no Brasil do século XIX. São Paulo: Companhia das Letras. 1993.

STEPAN, Nancy Leys.

A hora da eugenia: raça, gênero e nação na América Latina. Rio de Janeiro: Fiocruz. 2005.

WEGNER, Robert; SOUZA, Vanderlei Sebastião de. Eugenia "negativa", psiquiatria e catolicismo: embates em torno da esterilização eugênica no Brasil. História, Ciências, SaúdeManguinhos, v.20, n.1, p.263-288. 2013. 


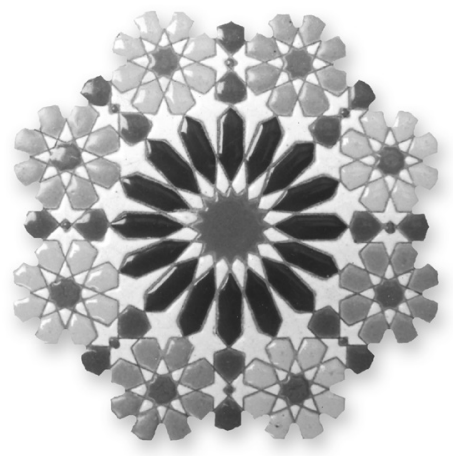

